\title{
Association between depression and body mass index in patients with chronic obstructive pulmonary disease
}

\author{
Athanasios Tselebis ${ }^{1 *}$, Dionisios Bratis ${ }^{1}$, Maria Harikiopoulou², Elpida Theodorakopoulou², Georgios Moussas ${ }^{1}$, \\ Athanasios Karkanias', Elias Kainis², Epaminondas Kosmas' ${ }^{2}$ Nikolaos Tzanakis ${ }^{3}$, Nikolaos Siafakas ${ }^{3}$ \\ From $1^{\text {st }}$ International Congress on Neurobiology and Clinical Psychopharmacology \\ and European Psychiatric Association Conference on Treatment Guidance \\ Thessaloniki, Greece. 19-22 November 2009
}

\section{Background}

It is well known that Chronic Obstructive Pulmonary Disease (COPD) is a disease with psychological comorbidities [1,2]. Especially depression (which its prevalence ranging between $10 \%$ and $42 \%$ ) affects physical functioning in these patients and may lead to increased risk of COPD exacerbations and rehospitalization [3]. Depression characterized, among other symptoms, by a significant weight loss or weight gain or decrease or increase in appetite nearly every day. Aim of the study is to investigate the association between depression and Body Mass Index (BMI) in patients with COPD.

\section{Materials and methods}

The study was performed in one of the largest hospitals in Greece and included 119 (95 male and 24 female) outpatient with COPD. The patients responded to the Beck Depression Inventory (BDI). BMI, age and education level were also recorded.

\section{Results}

Mean age and mean education level were $65.21( \pm 7.99)$ and $11.05( \pm 4.22)$, respectively, with no statistical difference as to genders (T-test $\mathrm{p}>0.05$ ). Mean BDI score was $11.69( \pm 7.54)$, while a percentage of $52 \%$ presented with moderate to severe depression. The percentage of women with positive BDI score was increased compared with that of men $(x 2 p=0.05)$. Mean BMI was $27.22( \pm 4.71)$, while a percentage of $59.6 \%$ presented BMI $>25$ (with no differences between genders). Regarding the total sample, no

\footnotetext{
${ }^{1}$ Psychiatric Department, Sotiria General Hospital of Chest Diseases, Athens,
} Greece correlation was observed between age, education level, BMI and BDI score (Pearson correlation $\mathrm{p}>0.05$ ). However, separating the subjects as to gender, we observed a positive correlation between BMI and BDI score in women (spearman correlation $\mathrm{p}<0.05$ ).

\section{Conclusions}

This study confirms the high prevalence of depression in COPD patients, and especially in women. Additionally, the association between depression and BMI seems to be clearer in female gender. However, further studies are required in order to clarify these findings.

\section{Author details}

${ }^{1}$ Psychiatric Department, Sotiria General Hospital of Chest Diseases, Athens, Greece. ${ }^{2}$ Pulmonary Rehabilitation Centre, Sotiria General Hospital of Chest Diseases, Athens, Greece. ${ }^{3}$ Department of Thoracic Medicine, University of Crete Medical School, Heraklion, Greece.

Published: 22 April 2010

\section{References}

1. Moussas G, Tselebis A, Karkanias A, Stamouli D, llias I, Bratis D, VassilaDemi $K$ : A comparative study of anxiety and depression in patients with bronchial asthma, chronic obstructive pulmonary disease and tuberculosis in a general hospital of chest diseases. Ann Gen Psychiatry 2008, 7:7.

2. Maurer J, Rebbapragada V, Borson S, Goldstein R, Kunik M, Yohannes AM, Hanania NA: Anxiety and Depression in COPD. Chest 2008, 134:43S-56S.

3. de Voogd JN, Wempe JB, Koëter GH, Postema K, van Sonderen E, Ranchor AV, Coyne JC, Sanderman R: Depressive symptoms as predictors of mortality in patients with COPD. Chest 2009, 135(3):619-25.

doi:10.1186/1744-859X-9-S1-S160

Cite this article as: Tselebis et al:: Association between depression and body mass index in patients with chronic obstructive pulmonary disease. Annals of General Psychiatry 2010 9(Suppl 1):S160. 